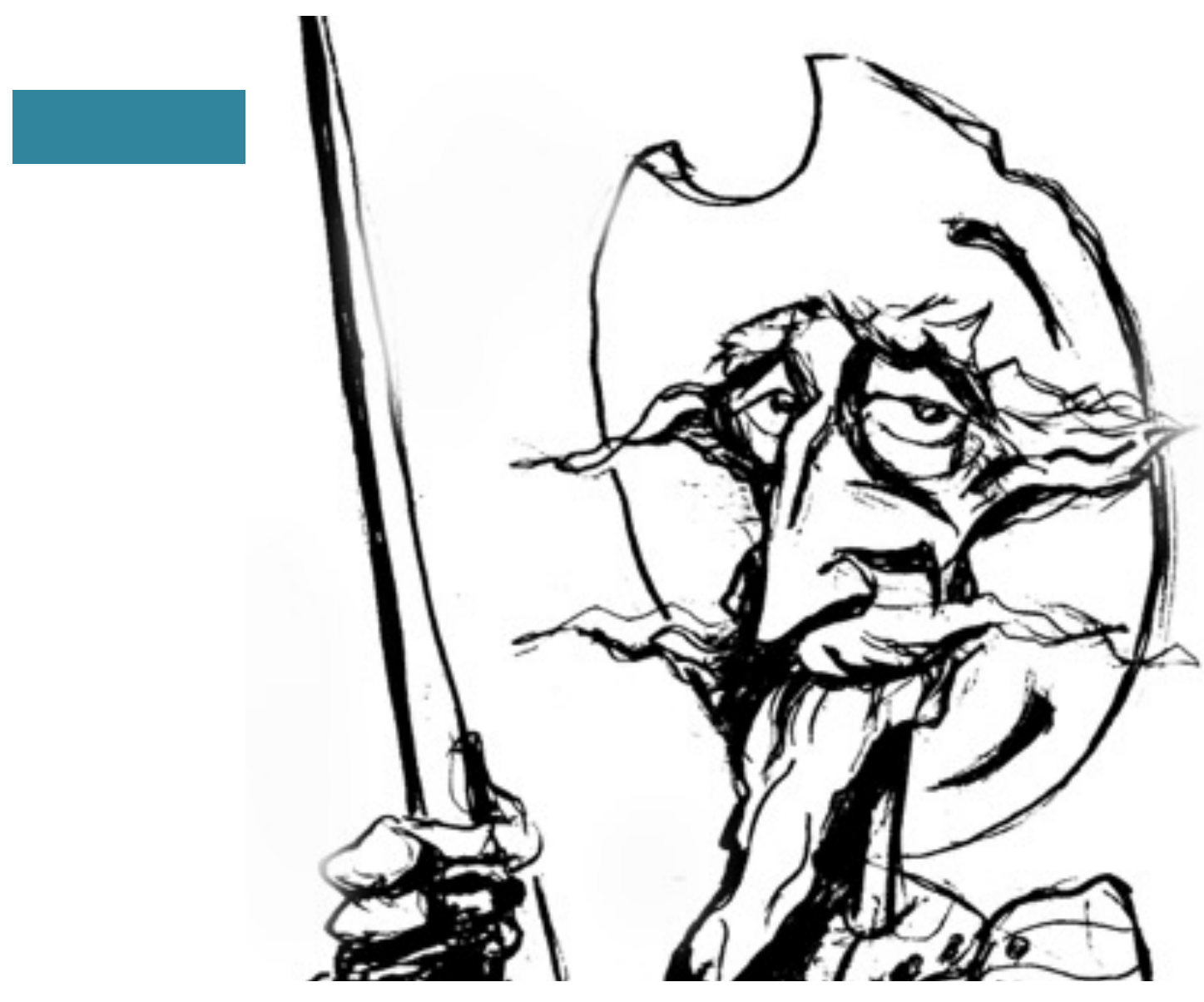

Los usos del "genocidio cultural" en los exilios español antifranquista y argentino de la última dictadura militar (1953-1981)

[Silvina Jensen] 


\title{
Los usos del "genocidio cultural" en los exilios español antifranquista y argentino de la última dictadura militar (1953-1981)*
}

\section{The Uses of "Cultural Genocide" in the Spanish Anti-Franco and Argentine of the Last Military Dictatorship Exiles (1953-1981)}

\author{
SILVINA JENSEN
}

\section{Resumen}

El artículo problematiza los usos del "genocidio cultural" en los lenguajes de denuncia de los exilios antifranquista español y argentino de la última dictadura militar. Parte de la hipótesis de que entre 1953 y 1981 ambos exilios agitaron esa noción apelando sea a su contenido jurídico, sea a su potencial polémico, táctico o retórico y al servicio de diferentes causas. El trabajo está organizado en tres partes. Las primeras atienden a las preguntas de quiénes la usaron, en qué espacios y con qué efectos al interior del campo de la oposición antidictatorial. La tercera reconstruye los contextos de uso, haciendo hincapié en los momentos de la acción colectiva exiliar y las diferentes coyunturas dictatoriales.

\section{Palabras clave}

"Genocidio cultural" - Lenguajes de denuncia Exilio español antifranquista - Exilio argentino del "Proceso de Reorganización Nacional" Comparación

\section{Abstract}

This article problematizes the uses of the "cultural genocide" in the languages of denunciation of the Spanish anti-Franco and the last Argentina military dictatorship exiles. It starts from the hypothesis that between 1953 and 1981 both exiles agitated that notion appealing either to its legal contents to its controversial, tactical or rhetorical potential, and to the service of different causes. The article is organized in three parts. The first two deal with the questions of who used that notion, in what spaces and with what effects within the field of antidictatorial opposition. The third reconstructs the contexts of use, emphasizing the moments of exiled collective action, and the different dictatorial conjunctures.

\section{Key words}

"Cultural genocide" - Languages of denunciation - Anti-Franco Spanish exile Argentine exile of the "Process of Reorganization National" - Comparison

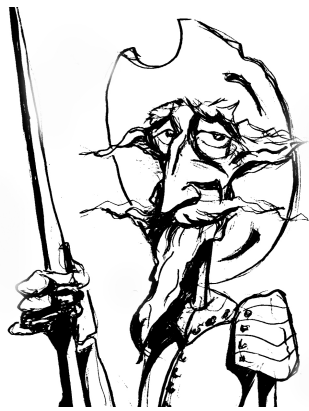

Recibido con pedido de publicación el 30 de noviembre de 2017

Aceptado para su publicación el 30 de marzo de 2018

Versión definitiva recibida el 20 de abril de 2018

Silvina Jensen, Universidad Nacional del Sur, Consejo Nacional de Investigaciones Científicas y Técnicas, Argentina; e-mail: sjensen@criba.edu.ar

\footnotetext{
*Agradezco los comentarios de los evaluadores anónimos de esta publicación.

Esta obra se publica bajo licencia Creative Commons. Atribución-NoComercial-CompartirIgual $(\mathrm{cc})$ EY-NC-SA Internacional

Jensen, Silvina Los usos del "genocidio cultural" en los exilios español antifranquista y argentino de la última dictadura militar (1953-1981), Prohistoria, Año XXI, núm. 29, jun. 2018, pp. 135-152.
}

\section{Consideraciones preliminares}


En un contexto de eclosión de usos jurídicos ${ }^{1}$ y académicos ${ }^{2}$ de la noción de "genocidio" en el mundo occidental, este trabajo hace foco en los usos públicopolíticos del "genocidio cultural" de cara a analizar cómo los exiliados republicanos españoles y los argentinos del último gobierno pretoriano hicieron de esa categoría una herramienta eficaz para denunciar, perseguir y sancionar la magnitud y cualidad represiva del régimen franquista (1939-1975) y del "Proceso de Reorganización Nacional" (1976-1983).

Conscientes de estar pisando un terreno por demás cenagoso, ya que como afirma Jorge Marco la cuestión del "genocidio cultural" constituye una de las "polémicas más extendidas en los genocide studies", ${ }^{3}$ este trabajo no pretende incidir en el análisis de su pertinencia jurídica, ni tampoco en el de su productividad analítica para la elucidación del pasado reciente.

El artículo intenta identificar en un periodo delimitado por el ingreso de la España franquista en la Organización de las Naciones Unidas para la Educación, la Ciencia y la Cultura (UNESCO) (30/1/1953) y la articulación en las filas del exilio argentino de la idea de un "Núremberg" para los responsables de las sistemáticas violaciones de los Derechos Humanos (19781981), quiénes utilizaron esa categoría como parte del arsenal de lucha políticohumanitaria, político-antidictatorial y político-identitaria en la esfera internacional; cuáles fueron los destinatarios privilegiados de ese uso públicopolítico (organismos internacionales humanitarios, connacionales, foros intelectuales, políticos); y cuáles los efectos de ese uso tanto hacia el interior de la oposición antidictatorial (en el país y en el exterior), como en el cerco del régimen autoritario. En el cierre, el trabajo intenta historizar la comparación, identificando en qué contextos dictatoriales, internacionales y de la propia dinámica del destierro, fue agitada la noción de "genocidio cultural" por parte de los exiliados españoles y argentinos.

\footnotetext{
${ }^{1}$ Sobre usos jurídicos de "genocidio" en casos de alta repercusión internacional como los de Augusto Pinochet, Sadam Hussein o Slobodan Milosevic, véase SEMELIN, Jacques Purificar y destruir. Usos políticos de las masacres y genocidio, UNSAM, Buenos Aires, 2013. En Argentina, los casos más resonantes de condenados por "delitos de lesa humanidad cometidos en el marco del genocidio" en la última década son los del ex capellán de la Policía de la Provincia de Buenos Aires, Christian von Wernich, y el del ex jefe de la Policía de la Provincia de Buenos Aires, Miguel Osvaldo Etchecolatz.

2 Para una aproximación a este debate en sede académica, véanse entre otros: FEIERSTEIN, Daniel Seis estudios sobre genocidio. Análisis de las relaciones sociales: otredad, exclusión y exterminio, Eudeba, Buenos Aires, 2000 y El genocidio como práctica social. Entre el nazismo y la experiencia argentina, FCE, Buenos Aires, 2007; ÁGUILA, Gabriela "La represión en la historia reciente argentina: Perspectivas de abordaje, conceptualizaciones y matrices explicativas", en Contenciosa, núm. 1, Santa Fe, 2013, pp. 1-13, [En línea] Disponible en: http://www.contenciosa.org/Sitio/VerArticulo.aspx?i=7; MARCO, Jorge "Genocidio y 'genocide studies': Definiciones y debates", en Hispania Nova. Revista de Historia Contemporánea, núm. 10, Madrid, 2012, pp. 1-39. [En línea] Disponible en: http:/ / hispanianova.rediris.es

${ }^{3}$ Marco afirma que Raphael Lemkin nunca empleó dicho término aunque reconoció "diferentes técnicas de aniquilación que incluían además de los asesinatos en masa, políticas de destrucción biológica y cultural. En la Resolución de las Naciones Unidas de 1946 se hacía una referencia explícita a este asunto, señalando que el genocidio "causa grandes pérdidas humanas en la forma de cultura y otras contribuciones. El término "genocidio cultural" apareció por primera vez en un borrador elaborado por el Ad Hoc Comittee encargado de confeccionar la Resolución de las Naciones Unidades de 1948, aunque dicha referencia fue finalmente enmendada. Diferentes países, liderados por los EEUU, se opusieron radicalmente ante el temor de que dicha mención permitiera la rebelión jurídica de las minorías. La referencia a la cultura quedó finalmente diluida en una breve y controvertida frase en la que se señalaba que el genocidio podía causar "daños graves físicos o mentales de los miembros del grupo", MARCO, Jorge "Genocidio...", cit., pp. 20-21.
} 
Esta aproximación comparada a los usos del "genocidio cultural" en los exilios antifranquista y argentino antidictatorial permitirá identificar cambios, continuidades y quiebres en las matrices ideológicas que atravesaron su puesta en acto con fines retóricos, metafóricos, polémicos y tácticos.

El trabajo parte de la hipótesis de que en plena Guerra Fría, el uso de la noción de "genocidio cultural" expresó la convivencia tensa de diferentes matrices ideológicas. Por un lado, ciertos usos de la noción de "genocidio cultural" abrevaban en las luchas antifascistas porque para los exiliados liberales, catalanistas y de izquierdas, el franquismo representaba la oprobiosa continuidad de un régimen que salió indemne delos enfrentamientos de los Aliados contra el Eje en la Segunda Guerra Mundial.

Por otro lado en el contexto de la Resolución 1514 (X) (14/12/1960) de la Asamblea General de las Naciones Unidas sobre la concesión de la independencia a los países y pueblos coloniales, esa matriz antifascista se prolongó o resignificó ${ }^{4}$ al calor de las luchas por la liberación nacional en territorios exteriores a Europa y en el marco de las críticas de la izquierda a la opresión del imperialismo en países como Vietnam o Argelia, y en no menor medida al apoyo estadounidense a las dictaduras de la Doctrina de la Seguridad Nacional de Cono Sur y Centroamérica (1970-1980). En este escenario, la noción de "genocidio cultural" permitió a estos exilios denunciar los procesos de desnacionalización violenta, las políticas de despersonalización por persecución de la lengua y cultura vernáculas, la destrucción sistemática del pensamiento y la creación libre y combativa (y no solo de sus producciones sino de sus cultores), y en no menor medida, las formas sutiles y perversas de cooptación selectiva y desde arriba de la voluntad popular mediante estrategias fascistas como la agitación del nacionalismo deportivo o por medidas supuestamente liberalizadoras en lo político o cultural, que siempre resultaron selectivas y que no excluyeron la aplicación simultánea de nuevas prohibiciones y nuevos dispositivos de orden público.

Por último no hay que olvidar que en esas décadas, el mundo occidental asistía al despertar del recuerdo del Holocausto tras una etapa de "silencio y marginación" de las voces de los sobrevivientes. Como explica Traverso, la celebración del juicio a Adolf Eichmann en la Corte del Distrito de Jerusalén imputado por "delitos de guerra, contra el pueblo judío y contra la Humanidad" y condenado a muerte por "genocidio" en diciembre de 1961- fue un punto de inflexión que en los años ochenta y sobre todo después de la Caída del Muro de Berlín habilitó no solo que la "memoria de la Shoah" se transformara en la nueva "religión civil" del mundo occidental, sino que el "mantel ideológico de los derechos humanos" se convirtiera en la única matriz legítima de la acción colectiva. ${ }^{5}$ En esta línea, desde los años sesenta y sobre todo setenta y ochenta del siglo pasado, la noción de "genocidio cultural" no solo sirvió para la lucha política exiliar (contra la ocupación fascista, por la emancipación nacional y social, contra el imperialismo y las diversas formas de opresión colonial, contra los neofascismos en países dependientes), sino para mostrar que los regímenes dictatoriales denunciados venían produciendo

\footnotetext{
4 Según Traverso, en los años 1960, "el compromiso anticolonialista no era sino una prolongación del antifascismo". En el contexto de las guerras antiimperialistas, "la comparación entre los crímenes nazis y las violencias coloniales atraviesa los escritos de Frantz Fanon e incluso las declaraciones del Tribunal Rusell sobre Vietnam". TRAVERSO, Enzo Els usos del passat. Història, memoria, política, PUV, Valencia, 2006, p. 114.

5 TRAVERSO, Enzo A sangre y fuego. De la guerra civil europea 1914-1945, Prometeo, Buenos Aires, 2009, p. 11.
} 
víctimas por miles, y que esas eran víctimas "indefensas" o "inocentes", cuyas trayectorias trágicas comenzaron poco a poco a desestimar aquella condición de "combatiente", "resistente", "luchador" o "guerrillero" que las matrices antifascista y anticolonialista venían enfatizando.

En definitiva, entre 1953 y 1981 los usos del "genocidio cultural" realizados por los exiliados catalanes y argentinos expresaban tanto la tensión entre matrices ideológicas que al final del siglo XX comenzaron a plantearse como excluyentes (la revolucionaria y antiimperialista y la humanitarista liberal); como el solapamiento de imaginarios capaces de convivir bajo aquella categoría ético-política que construyó escenas polémicas hacia afuera (regímenes dictatoriales) y hacia adentro (la oposición antidictatorial en el país y fuera del país).

\section{Los exiliados catalanes y los usos del "genocidio cultural"}

Si bien el intento de los exiliados por singularizar la situación represiva de Cataluña en el marco de la derrota de la República en la Guerra Civil española fue muy temprano, la formalización de la denuncia bajo la figura del "genocidio cultural" no se produjo sino hasta que la rehabilitación internacional del gobierno de Franco sepultó las esperanzas de una intervención inminente de las potencias democráticas para poner fin a ese gobierno "totalitario y fascista" que no solo había apoyado al Eje y amparado a criminales de guerra nazi, sino que perseguía a los republicanos dentro y fuera de las fronteras del Estado.

En noviembre de 1952 mientras la UNESCO debatía la admisión de España, desde Londres, Josep María Batista i Roca ${ }^{6}$ reafirmaba que Cataluña sufría no solo la completa desaparición del uso de la lengua catalana en todos los niveles educativos y de la administración pública, en el ámbito de la Justicia y en las publicaciones periódicas (deportivas, infantiles, científicas, políticas); sino también la disminución del número de libros publicados en catalán por el régimen de censura y la baja general del nivel intelectual de la ciudadanía.

Esta figura central de la internacionalización de la cuestión catalana cuestionaba que ninguna "motivación política" podía "justificar la brutal persecución contra una lengua y una cultura que no es de derecha ni de izquierda, sino que es de un pueblo milenario que se ve así ultrajado en el primero de sus derechos". ${ }^{7}$ Tras denunciar que la persecución se ejercía de "hecho" y de "derecho" contraviniendo los "principios de la UNESCO" y la "Declaración Universal de Derechos Humanos", Batista i Roca ${ }^{8}$ señalaba que el régimen franquista constituía un caso excepcional en Europa, frente al que no cabían excusas como la de ser un tema de ámbito "doméstico", en tanto encubría el intento sistemático y premeditado de destrucción completa de los valores fundamentales de un pueblo9.

\footnotetext{
${ }^{6}$ Historiador y militante catalanista que en los años 1930 alcanzó gran renombre en círculos del movimiento de nacionalidades europeo. Tras la derrota republicana se desempeñó como secretario de Carles Pi i Sunyer en el Consell Nacional de Catalunya de Londres (1939-1944), desarrollando una intensa relación con las comunidades catalanas de América.

7 "Catalanss'adreçan a 1' UNESCO", s.l, s.f. Fondo Jordi Arquer, Centre d'Estudis Histórics Internacionals (CEHI). Barcelona. Todas las traducciones del catalán al castellano del artículo son mías.

${ }^{8}$ Roca firmó el Memorandum on the anti-Catalan policy of General Franco's government junto a Josep Carner-Ribalta, Lluís Nicolau d'Olwer, Rafael Patxot i Jubert y Manuel Serra i Moret, que fue presentado en París en la $7^{\circ}$ Asamblea de la UNESCO.

9 “Catalanss'adreçan a l'UNESCO”, cit.
} 
La visibilización internacional de la situación represiva catalana como "genocidio cultural" fue el resultado de la acción de una nueva organización de la oposición democrática, catalanista y de izquierda surgida de la reunión en México de la Conferencia Nacional Catalana (11-13/9/1953).

Si bien la propuesta de recuperar una representación institucional y democrática amplia venía planteándose desde la disolución del último gobierno catalán en el exilio, fue en 1953 -a impulso de entidades catalanistas radicales de América, con apoyo del Front Nacional de Cataluña y bajo la gestión de figuras como Salvador Armendares ${ }^{10}$, Batista i Roca, Miquel Ferrer ${ }^{11}$ o Joan Massot $^{12}$ (personajes con amplia interlocución con sectores catalanistas, liberales y de izquierdas de las diferentes geografías del exilio, incluido países del Cono Sur de América y en particular Argentina ${ }^{13}$ ) - cuando se creó el Consell Nacional Catalá (CNC) de México. Como órgano ejecutivo de coordinación entre las fuerzas de la resistencia interior y los demócratas "catalanes ausentes de la Patria" para crear una sola política de oposición al régimen franquista, su accionar internacional destacó por su voluntad de denunciar que la represión franquista en Cataluña debía ser entendida como una represión singularizada por la sistemática persecución y el intento de destrucción de la "personalidad nacional catalana", vehiculizada por su lengua nativa.

A lo largo de las décadas de 1950, 1960 y 1970, el CNC se encargó de llevar a las asambleas bianuales de la UNESCO, la Comisión de Derechos Humanos, la Subcomisión de Prevención de la Discriminación y Protección de las Minorías o el Comité de Territorios No Autónomos, pero también ante el PEN Club Internacional o la Unión Federalista de las Comunidades Nacionales Europeas, peticiones y memorándums denunciando la política franquista de "despersonalización" y "genocidio" que operaba sobre el idioma, la cultura y las instituciones científicas catalanas. ${ }^{14}$

Un somero análisis de las acciones de los sectores del exilio antifranquista, nucleados en el $\mathrm{CNC}$ en pos de la de internacionalización de la cuestión catalana bajo la figura del "genocidio cultural", permite arribar a las siguientes conclusiones.

En primer lugar, que desde las primeras denuncias, los exiliados antifranquistas catalanes apelaron a los fundamentos jurídicos del "genocidio cultural". Así, en 1955 mientras la Comisión de Derechos Humanos de las

\footnotetext{
${ }_{10}$ Viejo militante de Esquerra Republicana de Catalunya e integrante del primer CNC de Londres, Armendares presidió el CNC de México hasta 1964.

${ }^{11}$ Miquel Ferrer había militado en el comunismo catalán (Partit Socialista Unificat de Catalunya) hasta la firma del Pacto germano-soviético. En 1940, participó junto a Serra i Moret en la constitución del Moviment Social d’Emancipació Catalana y fue secretario del CNC de México por más de una década. También fue parte del Pacto Galeuzca y referente de la Unión General de Trabajadores en Cataluña. Colaboró activamente con la revista porteña Ressorgiment.

${ }^{12}$ Massot militaba en Estat Català. Formó parte del CNC de Londres (Consell Pi i Sunyer) y del Front Nacional de Catalunya de París, apoyando tanto acciones de resistencia política como armada. Asimismo, junto a Batista i Roca desplegó una intensa labor internacional ante la UNESCO. Tenía una fuerte relación con Argentina donde había residido antes de la guerra civil.

${ }^{13}$ Desde Buenos Aires, los sectores representados fueron por un lado el que nucleaba Hipólit Nadal i Mallol desde las revista Ressorgiment; y por el otro, el Grup Joventut Catalana de la República Argentina, surgido en 1952 e integrado por segundas generaciones del exilio e hijos o nietos de la emigración, todos abiertamente partidarios de la independencia de Cataluña en el contexto de los procesos revolucionarios latinoamericanos post Revolución Cubana y de descolonización del Tercer Mundo.

14 "L'acció internacional del CNC", en Ressorgiment, n 554, Buenos Aires, setembre 1962, p. 8906.
} 
NNUU discutía un anteproyecto de Declaración de los Derechos de los Pueblos, ${ }^{15}$ Batista i Roca consultaba en forma "estrictamente confidencial" a Raphael Lemkin sobre las posibilidades que tenían los catalanes de encuadrar la denuncia de la política antifranquista bajo esta figura jurídica. Batista i Roca preguntaba a Lemkin si la situación de los catalanes -que no involucraba un "genocidio físico como el de los judíos de Alemania"-, podía igualmente entrar bajo el paraguas de la normativa onusiana, en tanto constituía un "genocidio espiritual y el intento de destruir la cultura y la lengua de un pueblo". ${ }^{16}$

En las décadas de 1950 y 1960, en reiteradas ocasiones, los exiliados catalanes plantearon la importancia de las nuevas instituciones del gobierno mundial, el nuevo entramado legal internacional y el aparato de conceptos doctrinales surgido en la segunda posguerra mundial, entre los que destacaban el de "genocidio" y su eficacia para plantear la cuestión catalana. En 1959, la revista Catalunya de Buenos Aires publicaba las apreciaciones de una figura clave del exilio catalán en Argentina. Joan Cuatrecasas afirmaba que en

“en otros tiempos las razas se dedicaban a exterminarse unas a otras. Cabe esperar que el antisemitismo hitleriano sea la última manifestación de esta plaga hoy denominada genocidio. La invención de tal palabra señala una fuente de progresos, la definición de una crueldad, el análisis de su significación y la condena universal del crimen colectivo. [...] Hoy las razas (mejor dicho, los pueblos) se desvelan y enderezan para autocultivarse, conservar la personalidad colectiva y revalorizar su psicología colectiva. Es esta la base jurídica del fenómeno político de la autodeterminación." 17

Si para Cuatrecasas, la noción de "genocidio" era parte de esa "revolución doctrinaria" que estaba en la base de la aparición de las nuevas estructuras supranacionales para la internacionalización de la cultura y la protección y defensa de aquellas que eran discriminadas, para un joven nacido en la posguerra e integrante de la segunda generación del exilio, Víctor Castells, esa categoría era el instrumento conceptual más idóneo para desnudar la verdadera naturaleza de la represión franquista sobre Cataluña, en sus faces destructiva y productiva ${ }^{18}$.

\footnotetext{
${ }^{15}$ Así como en 1955 algunos sectores del exilio catalán celebraron el anteproyecto discutido en las NNUU porque amparaba los derechos de los pueblos a "vivir y regir libremente su vida", "desarrollar y perfeccionar su personalidad nacional, económica y social", "su lengua y su cultura" y a la "autodeterminación"; en 1976, pretendieron recurrir a la "Carta de Argel", exigiendo la eliminación de todo enclave autoritario en Cataluña, sobre todo aquellos que comprometían la identidad o la integridad de su pueblo. D'OLWER, Nicolau "Sessió de la Subcomisió per a la Prevenció de les Discriminacions i Protecció de les Minoríes", s.l, sf., Fondo Nicolau d'Olwer, CEHI.

Recordemos que estos sectores del exilio antifranquista se integraron al movimiento que desde la guerra de Vietnam intentaba democratizar las relaciones internacionales y poner freno al imperialismo. En enero de 1976, en la última sesión del Tribunal Russel II que juzgaba los crímenes de las dictaduras latinoamericanas, varios de los referentes del exilio catalanista participaron en la creación de la Liga Internacional de los Derechos de los Pueblos, que en julio aprobó la Declaración Universal de los Derechos de los Pueblos (Carta de Argel).

${ }_{16}$ BATISTA I ROCA, Josep "Carta a Nicolau d'Olwer", Londres, 31/1/1955. Fondo Manuel Serra i Moret, CEHI.

${ }^{17}$ CUATRECASAS, Joan “De cara al món. La crisi contemporània", en Catalunya, núm. 62-63, Buenos Aires, febrer-març 1959, p. 16.

${ }^{18}$ CASTELLS, Víctor "Sobre el genocidi", en Ressorgiment, núm 524, Buenos Aires, març 1960, p. 8439.
} 
Siguiendo el planteo de Castells, quiero avanzar a la segunda cuestión relativa al uso del "genocidio cultural" entre los exiliados del CNC y en especial la identificación de sentidos y alcances diversos del término al interior del propio destierro. Castells consideraba que la eficacia del concepto no radicaba tanto (o solo) en lo que permitía captar "la dimensión épica de la agresión inconfesable de España y la defensa heroica de Cataluña", sino en lo que descubría de un franquismo que no solo "exterminaba" sino que "envenenaba poco o mucho el cuerpo colectivo": "un pueblo sometido a genocidio es un pueblo que es aniquilado en sus caracteres diferenciales. $Y$ es también un pueblo que se autoaniquila en la traición, la desorientación y la pasividad, alienado con ideas y sentimientos que le han sido inyectados"19.

En tercer lugar, la noción de "genocidio cultural" sirvió para desnudar que Cataluña era un territorio ocupado por un ejército extranjero y opresor, denuncia que en cierto modo entraba en contradicción con la introyección social del "genocidio" iluminada por Castells.

Si bien la calificación del franquismo como régimen "invasor" y "ajeno" a la sociedad catalana venía operando como una herramienta política útil para la denuncia internacional; en el contexto descolonizador de los años 1960 sirvió también para visibilizar la común condición de Cataluña con los países del Tercer Mundo. Así lo manifestaba Miquel Ferrer ante el Comité para la Información sobre los Territorios No Autónomos de NNUU, quien tras señalar que desde 1939 las provincias catalanas vieron liquidadas sus instituciones político-administrativas y económicas y prohibido el uso de su idioma materno (en escuelas, medios de comunicación y mundo editorial), denunciaba que

“Cataluña estaba sometida al centralismo más absoluto y a un trato colonial que afecta la personalidad nacional, que intenta despersonalizar a nuestro pueblo con una política genocida, prohibiendo nuestro idioma y persiguiendo nuestra cultura y nuestras instituciones científicas, perjudicando de gran manera nuestra economía y sometiendo a los obreros catalanes a un régimen sindical en flagrante contradicción con la Carta Universal de los Derechos Humanos y con los convenios de la OIT." 20

En ese contexto, Batista i Roca denunciaba el "plan sistemático de genocidio nacional" que había dejado a Cataluña en la condición de único territorio colonial de Europa. Y agregaba:

"Si Cataluña hubiese sido una colonia británica de África, aunque Inglaterra nos hubiese explotado en el pasado, después habría ayudado a nuestro desenvolvimiento y ahora seríamos un Estado independiente miembro de las NNUU. Porque nuestros vecinos son como son, hoy Cataluña es el único país de Europa sometido a una explotación colonial, la última colonia de Castilla." ${ }^{21}$

En cuarto lugar, la noción de "genocidio cultural" operó entre los exiliados catalanes como una forma tanto de denunciar que el franquismo era un vestigio totalitario en un mundo que se jactaba de haber derrotado a los fascismos y lo aceptaba en las instituciones del gobierno internacional pese a

\footnotetext{
${ }^{19}$ CASTELLS, Víctor “Sobre el genocidi”..., cit., p. 8440.

20 "L'acció internacional del CNC", cit., pág. 8906.

21 "Un article remarcable”, en Ressorgiment, núm. 547, Buenos Aires, febrer 1962, p. 8799.
} 
que continuaba violentando los principios onusianos y los compromisos contraídos con sus agencias especializadas (UNESCO), como de exponer su continuidad opresora con un nacionalismo castellano centenario. En tal sentido, como afirmaba Batista i Roca, el franquismo era apenas un capítulo de la "lucha secular de Castilla por la subyugación y asimilación de la periferia peninsular", aunque ningún régimen o gobierno previo (monarquía-república, dictadurademocracia) por más que hubiese utilizado métodos destructivos alimentados por su "nacionalismo castellano agresivo", era equiparable a la sistematicidad genocida del Caudillo. ${ }^{22}$

Pero si el "genocidio cultural" funcionó como arma de lucha antifranquista/antifascista y de movilización de la comunidad internacional a través de sus instituciones fundamentales, desde principios de los años 1960 sirvió también a las luchas por la autodeterminación de Cataluña y su liberación nacional y social. Como explicaba Batista i Roca, "los viejos mitos de República o Monarquía, de fascismo y antifascismo y las viejas fórmulas del regionalismo y la autonomía ya no sirven y han perdido todo tipo de fuerza entre las jóvenes generaciones de la posguerra que impulsan [...] la independencia". ${ }^{23}$ En este contexto puede comprenderse que el CNC solicitara al Comité de Descolonización de NNUU la aplicación de la letra completa del Capítulo XI (sobre territorios no autónomos) de la Carta de 1945, en lo relativo a la eliminación de toda forma de colonialismo no solo en los "territorios lejanos", sino también en los "metropolitanos" en aras del "principio general de la buena vecindad" y "teniendo debidamente en cuenta los intereses y el bienestar del resto del mundo en cuestiones de carácter social, económico y comercial". Por eso, el CNC reclamaba al Comité de Descolonización subsanar la contradicción generada entre una España miembro pleno de NNUU y su gobierno, opresor de "diversos pueblos con personalidad definida". ${ }^{24}$

Por último, la noción de "genocidio cultural" -ligada a una concepción de cultura como "alma", "personalidad" o "espíritu" de un pueblo vertebrado en torno a la lengua- fue para estos sectores del exilio catalán una forma de mostrar el plus represivo del franquismo sobre la región. ${ }^{25}$ A lo largo de estas décadas los exiliados pretendieron denunciar que los catalanes no solo eran perseguidos por "rojos", "republicanos", "catalanistas" o"demócratas", sino por catalanes. ${ }^{26}$ En esta línea, Batista i Roca reclamó ante la Unión Federalista de las Comunidades Nacionales Europeas, por la persecución que desde hacía 25 años venía sufriendo Cataluña en particular y las naciones no castellanas del Estado español en general (vascos, gallegos). En tal sentido, pidió se atendiera no solo a la política represiva en general, sino a aquella que tenía como blanco específico "el campo lingüístico, cultural y nacional" catalán. Sin desconocer que ese plus represivo afectaba también a las "otras naciones no castellanas" sometidas al mismo propósito de "destrucción nacional y lingüística" y de "asimilación a Castilla", Roca se atrevió a acuñar una nueva categoría, la de "genocidio

\footnotetext{
22 "Un article remarcable", cit., p. 8799.

23 "Un article remarcable", cit., p. 8799.

24 "L'acció internacional del CNC", cit., p. 8905.

25 Para una historiografía de la represión franquista sobre Cataluña y su comprensión en clave represión cultural y lingüística, véase VILANOVA i VILA-ABADAL, Francesc “La repressió franquista de postguerra en les obres generals d'història de Catalunya i en treballs de síntesi (1978-2000): una aproximació bibliográfica", en MIR, Contxita et al (edits.) Violència i repressió a Catalunya durant el franquisme. Balançhistoriogràfic $i$ perspectives, Servei de Publicacions de 1' Universitat de Lleida, Lleida, 2001, pp. 13-50.

26 "L'acció internacional del CNC", cit., p. 8905.
} 
cultural anticatalán" como herramienta de movilización de la opinión mundial a favor de la eliminación en Cataluña de toda "discriminación cultural, lingüística y nacional" y del "ejercicio del derecho de autodeterminación" de acuerdo con los principios de las NNUU. ${ }^{27}$

\section{Los exiliados argentinos y los usos del "genocidio cultural"}

En las filas del exilio argentino, el uso de "genocidio cultural" remite de forma diáfana al escritor Julio Cortázar, figura señera de la internacionalización de la situación represiva bajo los gobiernos del "Proceso de Reorganización Nacional", ${ }^{28}$ pero cuya expatriación no estaba vinculada a la persecución de la última dictadura militar. En realidad, Cortázar salió del país en 1951, agobiado por el clima político del peronismo y gracias a una beca del gobierno francés que acabó por convertirlo en uno de los escritores del boom de la Literatura latinoamericana en la Europa de los años sesenta. Su trayectoria intelectual indiscutida, las redes culturales y políticas a las que estaba integrado en Europa, su giro ideológico hacia la izquierda, convocado primero por la Revolución Cubana y más tarde porla Revolución Sandinista, provocaron que cuando los "fascismos dependientes" 29 impusieran el terror y la barbarie en el Cono Sur y Centroamérica, el autor de Rayuela pasara a ocupar un lugar eminente en la internacionalización de la escalada represiva en la región, convertido por el general Videla en uno de los principales agentes de "campaña antiargentina", y en una de las voces más reconocidas -junto a Mario Benedetti y Jacobo Timerman- de esa "minoría ruidosa" cuyos "ríos de tinta" alimentaban las páginas de la "prensa oficiosa" europea con "patrañas" contra la Nación. ${ }^{31}$

Entre junio de 1978 y febrero de 1981, Cortázar utilizó la expresión "genocidio cultural" en algunas conferencias y disertaciones en Europa ${ }^{32}$ y en América Latina. ${ }^{33}$

\footnotetext{
27 “Antecedents", en Ressorgiment, núm. 571, febrer 1964, p. 9103.

${ }^{28}$ Forma en que los militares argentinos designaron al gobierno que encabezaron entre el 24 marzo de 1976 y el 10 de diciembre de 1983. En adelante PRN.

${ }^{29}$ La revista Nueva Política de México dedicó su núm. 1 (enero-marzo 1976) a analizar el proceso "de fascistización" que vivía América Latina, un tipo de "fascismo atípico, sui generis, el fascismo dependiente o neofascismo". Cortázar fue uno de los colaboradores junto a Arthur Miller, Helio Jaguaribe, Darcy Ribeiro, Pedro Buscovic, Leopoldo Zea, Agustín Cueva, Marcos Kaplan.

${ }^{30}$ FEINMANN, José El mito del eterno fracaso, Legasa, Buenos Aires, 1985, p. 238.

${ }^{31}$ ZUCOTTI, Juan La emigración argentina contemporánea, a partir de 1950. Un testimonio fiel de la Argentina del exterior, Plus Ultra, Buenos Aires, 1987, p. 97.

${ }^{32} \mathrm{Me}$ refiero a la ponencia "El lector y el escritor bajo las dictaduras en América Latina" (Congreso del PEN Club internacional, Estocolmo, junio 1978), donde tras poner a debate el rol de la literatura en América Latina y las urgencias del lector del subcontinente, abogaba por una literatura que ofreciera "signos, indicaciones, preguntas" y "desnud[ara] nuestras realidades" y "nuestras debilidades", desvelando las "huellas de la identidad que buscamos". La responsabilidad del escritor estaba en enfrentar (desde cualquier forma de literatura, proselitista o no) el "oprobio, la violencia y hasta el genocidio físico y cultural" que vivía el continente, bajo el imperio de dictaduras sostenidas por el imperialismo norteamericano. Pese a relativizar el impacto del trabajo del escritor frente al "horror y la opresión que presenta hoy el Cono Sur", Cortázar llamaba a no olvidar a ese lector que exigía de sus intelectuales "algo más que bellas historias, algo más que estilos depurados, algo más que palabras impresas". CORTÁZAR, Julio Argentina: país de alambradas culturales, Muchnik, Barcelona, 1984, pp. 46, 47.

${ }^{33}$ Entre el 29 de junio y el 9 de julio de 1978, se realizó en Cerizy-la-Salle el Coloquio "Literatura Latinoamericana de hoy", donde Cortázar presentó la ponencia "América Latina: exilio y literatura", origen de la polémica con la escritora argentina Liliana Heker.
} 
Aunque Cortázar no abundó en su uso público-político más allá de este conjunto de eventos de calado fundamentalmente cultural, su impacto admite puntos de comparación con los usos del "genocidio cultural" realizado por los políticos catalanistas en la esfera internacional en las décadas de 1950 y 1960. Ese impacto debe analizarse también como resultado del activismo antiimperialista y antidictatorial que llevó a Cortázar a formar parte del Tribunal Rusell II (Lelio Basso), del Tribunal Permanente de los Pueblos y del Coloquio Internacional sobre Desaparición Forzada de Personas realizado en París (31/1-1/2/1981). ${ }^{34}$

Curiosamente sus escasos usos se convirtieron en un reclamo periodístico, una forma de desnudar la naturaleza represiva de la dictadura argentina y casi inmediatamente en un motivo de polémica al interior del campo intelectual argentino.

Por un lado, desde la contemporaneidad del PRN y hasta bien avanzada la transición democrática, no pocos escritores argentinos y latinoamericanos de primera línea, residentes o de paso por las principales capitales del destierro (México, Madrid y Barcelona) fueron interrogados sobre la situación política argentina en base al diagnóstico cortaziano sobre la represión dictatorial. ${ }^{35}$ Por otro lado, el "genocidio cultural" de Cortázar operó como detonante de las llamadas "polémicas entre los que se fueron y los que se quedaron", ${ }^{36}$ aquellas

\footnotetext{
34 Reunión de activistas del mundo humanitario, hombres del mundo del derecho e intelectuales, el Coloquio discutió sobre la situación de 15 países (Bolivia, Brasil, Chile, Argentina, El Salvador, Guatemala, Nicaragua, Perú, México, Uruguay, Chipre, Etiopía, Indonesia, Filipinas, Sudáfrica) que bajo regímenes de excepción sufrían masivas y sistemáticas desapariciones forzadas e involuntarias de personas. La desaparición forzada fue el último recurso usado por esos Estados para deshacerse de sus opositores políticos, eludiendo todo tipo responsabilidad criminal frente a la comunidad internacional.

${ }^{35}$ Numerosos escritores hispanoamericanos se sumaron al debate de si América Latina sufría un “genocidio cultural”, entre otros: Mario Benedetti ("Frente al Genocidio cultural: crear cada vez más", La Vanguardia, Barcelona, 28/3/1980); Juan Goytisolo ("Reencuentro con el espacio perdido. Arenys de Munt", La Vanguardia, 22/6/1980); Gregorio Selser ("Argentina: ¿rige lo del genocidio cultural?" y "Argentina. Algo más sobre lo del genocidio cultural", El Día, México, 20/7/1980 y /4/8/1980) o Jorge Asís (La Nación, Buenos Aires y La Vanguardia, Barcelona, 29/9/1981).

El periodista argentino exiliado en Barcelona, Eduardo Goligorsky recordaba que en 1980 el escritor Ernesto Sábato reconocía el intento castrense de "genocidio cultural", pero afirmaba que pese a ello la cultura argentina continuaba existiendo y que era una verdadera injusticia pensar al país como un "tremendo cementerio" (Clarín, Buenos Aires, 7/7/1980). Al mismo tiempo recogía un intercambio entre los escritores Gabriel García Márquez (colombiano) y Manuel Mujica Láinez (argentino) en el que el primero señalaba la cantidad de escritores "desaparecidos" y el segundo que los grandes nombres de la literatura argentina (Jorge L. Borges, Ernesto Sábato, Adolfo Bioy Casares, Silvina Ocampo, Mallea) no se habían ido del país. GOLIGORSKY, Eduardo Carta abierta de un expatriado a sus compatriotas, Sudamericana, Buenos Aires, 1983, p. 38.

Por su parte, el escritor Osvaldo Bayer, exiliado en Alemania, explicó que la expresión "genocidio cultural" "es un llamado dramático, claro y puro, con la limpia ingenuidad de quienes luchan con los perseguidos. No de los que se prosternan ante los poderosos, por más metáforas que agreguen a sus disimulos. El artículo de Cortázar ("América Latina: exilio y literatura") es de mera agitación. Nada menos. Un documento de guerra. Lo escribió para ayudar a los acosados de afuera y adentro. No hay una sola frase que hable de divisiones entre los que tuvieron que irse y los que se quedaron, de superioridades, de menosprecios". BAYER, Osvaldo "Pequeño recordatorio en un país sin memoria", en Rebeldía y esperanza, Zeta, Buenos Aires, 1993, p. 294.

${ }^{36}$ Por razones de espacio no entraré en el despliegue de las principales polémicas que hicieron foco en los efectos de la dictadura sobre el campo cultural argentino, incluyendo la existencia de un "genocidio cultural". Sobre las polémicas, véase JENSEN, Silvina "Vientos de polémica en Cataluña: los debates entre 'los de adentro' y 'los de afuera' de la Argentina de la última 
disputas que atravesaron el campo de la literatura argentina al menos entre 1978 y $1986^{37}$ y que tuvieron su origen en el ríspido intercambio entre Cortázar y Liliana Heker. ${ }^{38}$ La publicación de la ponencia "América Latina: exilio y literatura" en la revista colombiana Eco (núm. 205, noviembre 1978) fue recuperada tiempo después por Heker que le respondió en una revista literaria porteña de poca tirada, pero importante en el campo de la disidencia intelectual del régimen militar. El artículo de Heker titulado "Exilio y literatura" (El Ornitorrinco, Buenos Aires, núm. 7, enero-febrero 1980) fue reproducido por diversas publicaciones del exilio argentino en México (Controversia, núm. 11-12, abril 1981) y España (Testimonio Latinoamericano, Barcelona, núm. 2, mayo-junio de 1980 y Resumen de Actualidad Argentina, Madrid, núm. 28, 22/9/1980), que mantuvieron vivo el debate sobre "el genocidio cultural" al menos hasta finales de 1981.

En "América Latina: exilio y literatura", Cortázar volvía sobre el "genocidio cultural" para desnudar que el exilio era un mecanismo punitivo utilizado por los militares "para eliminar al adversario". Aplicado sobre los escritores e intelectuales representaba un golpe de gracia a la cultura, cuya producción y productores se veían atenazados por prácticas de censura, autocensura, destierro o muerte.

Sin embargo, lejos de asumir una postura autocompasiva, trágica y victimizante, Cortázar llamaba a convertir la "negatividad" de las dictaduras y de los exilios en un punto de apoyo para saltar hacia adelante, recuperar lo perdido, derrotar al enemigo y retornar a una Patria libre de déspotas y verdugos. ${ }^{39}$ Según Cortázar, para enfrentar a las dictaduras era necesario transformar la "carencia", "exclusión" y "despojo" del exilio en una "estrategia" y en un "arma de combate", "invirtiendo por completo el programa del adversario y saliéndole al frente de una manera que éste no podía imaginar" ${ }^{40}$

En este contexto, diagnosticar que Argentina (y América Latina) vivía un "genocidio cultural" -esto es, un intento de aniquilamiento del "pensamiento" y la "creación libres y combativos" e incluso de la "mera imaginación" por considerarla "criminal" 41 - fue para Cortázar parte de una estrategia meditada de "radicalidad" lingüística, ${ }^{42}$ en apariencia contraria a la lógica científica, pero

dictadura militar", en HMiC: Història Moderna i Contemporània, núm III, Barcelona, 2005, pp. 189209 [En línea] Disponible en: http:/ / www.raco.cat/index.php/HMiC/article/view/22069

37 Según algunos de los intelectuales, el Congreso de Maryland de diciembre 1984 y su homólogo porteño en el Centro Cultural General San Martín (agosto 1986) significaron la clausura de las polémicas. Sin embargo, tal como puede leerse en Tierra que anda. Los escritores en el exilio de Jorge Boccanera (Ameghino, Buenos Aires, 1999), buena parte de las lógicas, argumentos y dinámicas de las "polémicas del exilio" se han visto reeditadas en coyunturas más recientes, por caso el debate parlamentario sobre el proyecto de ley de reparación a los exiliados políticos del PRN (998).

${ }^{38}$ La respuesta inicial de Heker titulada "Exilio y literatura" (El Ornitorrinco, Buenos Aires, núm. 7, enero-febrero 1980) fue reproducida en Resumen de Actualidad Argentina de Madrid (núm. 28, 22/9/1980) y Testimonio Latinoamericano de Barcelona (núm. 2, mayo-junio 1980) y Controversia (núm. 11-12, abril 1981), abriendo varias líneas de debate y convocando a numerosos intelectuales argentinos en el país y el exilio.

${ }^{39}$ CORTÁZAR, Julio Argentina: país de alambradas culturales, Muchnik, Barcelona, 1984, p. 13.

${ }^{40}$ CORTÁZAR, Julio Argentina..., cit., pp. 12-13.

${ }^{41}$ CORTÁZAR, Julio Argentina..., cit., p. 11.

${ }^{42}$ Cortázar apostó por esa "radicalidad" lingüística en diversas oportunidades. En la Conferencia "Exilio y Solidaridad en América Latina" (Caracas, 1979) propuso avanzar hacia la creación de "un nuevo concepto del terror y la tortura", calificándolos de "enfermedades endémicas" en países como Argentina, Bolivia, Chile, Haití, Paraguay y Uruguay. CORTÁZAR, Julio "Al general no le gustan los congresos", Caracas, 1979. [En línea]. Disponible 
coherente con aquella que pretendía "transformar el disvalor del exilio" en un "valor de combate". ${ }^{43}$

A principios de 1981, la Association Internationale de Défense des Artistes victimes de la répression dans le monde (AIDA) ${ }^{44}$ publicaba Argentine: Une culture interdite (Pièces à conviction 1976/1980), ${ }^{45}$ en cuyo epílogo ${ }^{46}$ Julio Cortázar insistía en que "el genocidio cultural" (en sus "múltiples" y "encarnizadas" formas) tenía una "vigencia infame en la Argentina" aunque era resistido en "todos los planos". ${ }^{47}$

Si la noción de "genocidio cultural" permitió a Cortázar desnudar que los "regímenes fascistas" veían a la cultura como "subversiva", como "delito" o como "herejía" -porque estimulaba el pensamiento autónomo, crítico, imaginativo y combativo, comprometido con la realidad social del continente y "porque relata hechos verídicos" ${ }^{48}$ - la denuncia de la persecución de artistas, músicos, pintores, actores, cineastas, escritores y dibujantes era solo el medio para visibilizar el "genocidio, la persecución, la asfixiante falta de libertad y el malestar económico" que sufrían los 28 millones de argentinos". ${ }^{49}$ De este modo, la represión en el campo de la cultura (represión sectorial) era apenas un botón de muestra del potencial genocida del gobierno militar, ${ }^{50}$ aunque quizás uno de los "aspectos más repulsivos de la actual dictadura". ${ }^{51}$

En un contexto donde los militares buscaban cerrar legalmente el "problema de las desapariciones" 52 y cuando la comunidad internacional reconocía la tragedia argentina, la noción de "genocidio cultural" poco a poco pasó a operar como una estrategia sobre todo para denunciar la desaparición forzada de artistas, escritores, científicos y profesionales. Si bien ninguna modalidad coactiva, de disciplinamiento o represión física sufridas por artistas e intelectuales quedó excluida de la denuncia, la desaparición fue ocupando el centro de la escena y poco a poco referir al "genocidio" sobre el mundo de la cultura fue hablar de los escritores, músicos, artistas y educadores "desaparecidos".

en:http:/ / ronaldjq.blogspot.com.ar/2011/05/al-general-no-le-gustan-los-congresos.html

${ }^{43}$ CORTÁZAR, J. Argentina..., cit., p. 13.

${ }^{44}$ Sobre AIDA, véase CRISTIÂ, Moira "Solidaridad e identidad artística transnacional. Reflexiones sobre la experiencia de 1'Association internationale de défense des artistas victimes de la répression dans le monde (1979/1985)", en DE CRISTÓFORIS, Nadia y NOVICK, Susana (comps.) Jornadas Un siglo de migraciones en la Argentina contemporánea: 1914-2014, Instituto de Investigaciones Gino Germani, Buenos Aires, 2016, pp. 3-20.

${ }^{45}$ El título de la edición española fue Argentina: cómo matar la cultura, Revolución, Madrid, 1981.

${ }^{46}$ CORTÁZAR, Julio "El trigo pueblo y la pirámide del despotismo", en AIDA Argentina: cómo..., cit., pp. 269-271.

${ }^{47}$ CORTÁZAR, J. “El trigo...", cit., p. 271.

${ }^{48}$ AIDA “¿Por qué AIDA?”, en AIDA, Argentina: cómo matar..., cit., p. 273.

${ }^{49}$ ADELLACH, Alberto y AGUIRRE, Mariano "Prefacio a la edición en castellano", en AIDA, Argentina: cómo matar..., cit., p. 3.

${ }^{50}$ Cabe señalar que ya en el primer informe (1977) sistemático del exilio argentino, Argentina: Proceso al genocidio, elaborado por la Comisión Argentina de Derechos Humanos (CADHU), de la que Cortázar formaba parte, la "educación y la cultura" y la "prensa y los periodistas" aparecían como blancos privilegiados de la acción terrorista de un Estado que tenía su razón de ser en la "represión al movimiento obrero".

${ }^{51}$ ADELLACH, Alberto y AGUIRRE, Mariano "Prefacio a la edición en castellano", cit., p. 3.

${ }^{52}$ Leyes $22.062(5 / 9 / 1979)$ y $22.068(12 / 9 / 1979)$ con las que el gobierno militar presidido por el general de Jorge R. Videla declaraba legalmente muertas a las personas desaparecidas, supuestamente con fines previsionales y sucesorios. 
Mientras París acogía el Coloquio sobre la "Política de desaparición forzada de personas" -en el que Cortázar denunciaba que la "técnica" de la desaparición tenía el doble propósito de instalar el miedo en la sociedad y promover una falsa esperanza entre los seres queridos de las víctimas; y que su manifiesto carácter diabólico remitía en lo profundo a una dimensión absolutamente humana y argentina ${ }^{53}$-, AIDA lanzaba una campaña por "cien artistas argentinos desaparecidos". En esa circunstancia, Cortázar reclamó no claudicar ante los "cómplices" involuntarios del olvido (entre los que se encontraban algunas víctimas directas e indirectas y muchos argentinos que se beneficiaron con el régimen castrense o cayeron bajo la manipulación del fascismo) y ante los resignados que pedían el "paso a otra cosa" y el "retorno progresivo a la normalidad". ${ }^{54} \mathrm{Y}$ en cambio llamó a apostar por los caminos de la verdad y la justicia ${ }^{55}$ frente al despotismo. ${ }^{56}$

De este análisis se desprenden algunas conclusiones preliminares.

En el caso argentino, el artífice del "genocidio cultural" fue el escritor Julio Cortázar y sus usuarios (apoyos o detractores) prioritarios, actores vinculados al mundo intelectual (argentino y latinoamericano), pero cuya significación pública y política y su compromiso primero con los procesos revolucionarios y de emancipación nacional y social, y más tarde con las luchas antidictatoriales y a favor de los derechos humanos, no era desdeñable (de hecho no pocos de estos intelectuales fueron las voces de la denuncia de los regímenes dictatoriales de la región).

En segundo lugar, la noción "genocidio cultural" no parece haber tenido ningún contenido jurídico en el uso de los exiliados argentinos, ${ }^{57}$ aunque su agitación se dio en un contexto donde comenzó a articularse (aún de forma imprecisa) la perspectiva de un "juicio y castigo" para los responsables de las violaciones a los derechos humanos (en particular, de los perpetradores de

\footnotetext{
${ }^{53}$ La intervención de Cortázar titulada "Negación del olvido" daba cuenta de un aspecto clave del "genocidio" argentino. Como afirmaba Cortázar, lo más macabro era que los "verdugos" hablan "nuestro idioma", no son parte de una "ocupación extranjera". En el subcontinente, "la desaparición y la tortura son manipuladas por quienes hablan como nosotros, tienen nuestros mismos nombres y nuestras escuelas, comparten costumbres y gestos, provienen del mismo suelo y de la misma historia" y eso es lo que abre un "abismo" en el que no son posible el olvido y la impunidad y en cambio se impone "seguir reclamando por la verdad de su destino y por su aparición con vida”. CORTÁZAR, Julio Argentina..., cit., p. 20.

${ }^{54}$ CORTÁZAR, Julio “El trigo pueblo y la pirámide del despotismo”, cit., pp. 270-271.

${ }^{55}$ Según Cortázar, el Coloquio tuvo como objetivo buscar alternativas normativas en el derecho interno e internacional para enfrentar el crimen de la desaparición forzada. Desde 1979 y en forma más definida hacia el $5^{\circ}$ aniversario del golpe de Estado argentino (24/3/1981), la idea de un "Núremberg" comenzó a instalarse en el horizonte de expectativas de los exiliados. Incluso desde la reunión de París y sobre todo en el I y II Congresos Latinoamericanos de Familiares de Detenidos Desaparecidos (San José de Costa Rica y Caracas, enero y noviembre de 1981), el III Congreso de la Federación de Familiares de Desaparecidos (FEDEFAM) (Caracas, junio 1982), los exiliados argentinos discutieron proyectos de Convención Internacional sobre Desaparición Forzada de Personas. Véase FundaLatin, Los desaparecidos. Propuestas para un proyecto de Convención Internacional contra las desapariciones forzadas, s.e., Caracas, 1982.

${ }^{56}$ CORTÁZAR, Julio Argentina..., cit., pp. 19-20.

${ }^{57}$ Luciano Alonso afirma algo parecido cuando plantea que si el movimiento de Derechos Humanos durante la dictadura, la caracterizó como "genocida", no recurrió a aquellos instrumentos internacionales que permitían perseguir tal delito (Convención de las Naciones Unidas para la Prevención y la Sanción del Delito de Genocidio). ALONSO, Luciano "La definición de las ofensas en el movimiento por los derechos humanos en argentina y la calificación de "genocidio", en Contenciosa. Revista sobre violencia política, represiones y resistencias en la historia iberoamericana, núm. 1, p. 15. [En línea]

Disponible en http:/ / www.contenciosa.org/Sitio/NormasDePublicacion.aspx
} 
desapariciones forzadas) y a imaginarse un horizonte de condena penal para un futuro más o menos cercano (el "Núremberg argentino").

En cambio, pareció encerrar un uso retórico-político que operó dentro del proceso de revisión exiliar de las estrategias y repertorios de la denuncia en el mediodía dictatorial y cuando comenzaba a evaluarse la eficacia de los caminos ya transitados (apelación al entramado normativo humanitario internacional, recurso al derecho). ${ }^{58}$ Asimismo, la noción cortaziana de "genocidio cultural" no puede leerse sino en el contexto de otros usos metafóricos propuestos contemporáneamente por el autor de Rayuela (la del valor del exilio, la de la tortura como "enfermedad endémica" en Latinoamérica).

Sin embargo, mientras sus detractores hicieron de la metáfora una forma de la "exageración", ${ }^{59}$ una "mitificación", un "recurso lírico-demagógico" y un arbitrio retórico que permitía encubrir por partes iguales culpas y sentimientos de superioridad (mecanismo de autoheroización de los exiliados); para Cortázar, la apelación al humor, al sinsentido, a lo aparentemente irracional, a lo que contradecía aproximaciones analíticas o científicas y no daba cuenta de una lectura ajustada a la realidad, eran formas creativas de expansión de los límites de la denuncia, que por un lado, intentaban desnudar lógicas perversas, ocultas y negadas; $y$, por el otro, pretendían enfrentar al régimen pretoriano en su política simbólica de construcción falaz de la realidad, rechazando las identidades asignadas o invirtiendo sus valencias. En tal sentido, la denuncia del "genocidio cultural" era una respuesta a la omnicomprensiva noción de "subversión cultural" articulada por el PRN y una forma de señalar que la dictadura no solo intentó destruir, aniquilar, matar y silenciar la cultura, sino que también procuró proyectar nuevos valores e ideas, operando un proceso de "desidentificación nacional y cultural" y un divorcio del pueblo con sus "valores morales e históricos más esenciales", desde la inyección de un "nacionalismo barato" y "patriotero" que jugaba al servicio del imperialismo y de sus "armas de publicidad desaforada" y en "pos de una educación elitista y deformante".60

Por último señalar que el uso del "genocidio cultural" en los exiliados argentinos operó como una forma de denunciar la situación global de los pueblos de Latinoamérica, oprimidos por el imperialismo norteamericano y sus personeros, las dictaduras "fascistas". En tal sentido, si el "genocidio cultural" permitía denunciar la vulneración sistemática de los derechos individuales a la vida (muerte, desaparición) y la libertad (física, de creación, expresión, pensamiento, etc.) de los hombres y mujeres del campo de la cultura en cada

\footnotetext{
${ }_{58}$ En Bolonia, durante la creación del Tribunal Permanente de los Pueblos (1979), Cortázar insistió en una especie de división de funciones entre juristas y otros actores sociales para la defensa de los derechos de los pueblos. Planteó que los pueblos pueden aprender a ser conscientes de sus derechos por vías no necesariamente jurídicas, que en el caso de los países latinoamericanos, escapan a su comprensión inmediata de las gentes o son excluidos de su conocimiento por la censura o la tergiversación gubernamental. Esa consciencia puede florecer por las vía de la belleza, de la poesía, del humor, de la ironía, de la sátira, de la caricatura, de la imagen, del sonido, del grito dramático, del dibujo, del gesto, "de todo lo que toca directamente la sensibilidad popular y abre admirablemente paso al contenido lógico, moral e histórico de los enunciados formales". "Tribunal Permanent dels Pobles", en Agermanament, núm. 152, Barcelona, juliol-setembre 1979, pp. 93-94.

${ }^{59} \mathrm{Si}$ bien a su regreso a la Argentina (diciembre de 1983), Cortázar se retractó asumiendo que había cometido una exageración porque "genocidio es la desaparición de todo un pueblo", ratificó el sentido general de la noción convertida en estrategia eficaz contra las dictaduras.

${ }^{60}$ Las comillas remiten a ideas que Cortázar expresó en numerosas conferencias e intervenciones durante la dictadura y que podemos leer en Argentina, país de alambradas culturales.
} 
uno de los países, al mismo tiempo desvelaba cómo eran violentados los derechos de los pueblos latinoamericanos sometidos a una política sistemática y de largo aliento de injusticia, expoliación y sometimiento.

\section{Los usos del "genocidio cultural" en sus contextos}

Comprender la diversidad de usos y de espacios de interlocución en los que los exiliados antifranquistas del CNC y argentinos antidictatoriales agitaron la noción de "genocidio cultural" -siempre con propósitos denuncialistas, pero sosteniendo causas heterogéneas a lo largo de las décadas de 1950, 1960 y 1970 (el antifascismo, la liberación nacional y cultural, la propaganda nacionalista y la apuesta por la independencia política, los proyectos revolucionarios, la lucha por la emancipación de los oprimidos, la prédica del humanitarismo liberal y la defensa de los derechos a la vida, la libertad y la integridad de las víctimas bajo terrorismos de Estado) - obliga a hacer algunas puntualizaciones respecto a la situación política interna e internacional de las dictaduras y al papel jugado por los exiliados en la oposición antidictatorial y en el cerco internacional.

La pregunta que deberíamos responder es si el "genocidio cultural" fue agitado por los exiliados en idénticos o diferentes contextos internos y externos dictatoriales y en los mismos o distintos momentos de su acción colectiva exterior (momento de relevancia opositora o momento de reflujo).

Dejando pendiente un análisis pormenorizado de esos contextos es posible afirmar que:

1. Desde los años 1950, el rol político de los viejos exiliados catalanes republicanos era más testimonial que efectivo en su capacidad de torcer el rumbo a la dictadura de Franco y forzar el final del régimen. El curso inexorable del tiempo (las muertes en el destierro), la necesidad de re-articular una vida laboral y familiar en los países de acogida; y el golpe a la esperanza de un próximo retorno tras la no intervención de los aliados en España al final de la Segunda Guerra Mundial y la lenta pero sostenida rehabilitación internacional del régimen franquista, marcaron los derroteros de la oposición antifranquista en el exterior en las décadas de 1950 y 1960.

Si bien la generación de exiliados de la guerra siguió produciendo hechos políticos, desplegando una labor de internacionalización de la cuestión catalana (región que a su juicio sufría una doble represión política y nacional), a ella se sumaron los nacidos en la posguerra, esos jóvenes que desde mediados/fines de los años 1950 se organizaron en todas las geografías de la diáspora (y también en el interior) para cuestionar la tibieza opositora de sus padres, sus claudicaciones frente al republicanismo español en lo relativo a la denuncia del hecho diferencial franquista en Cataluña, apostando por nuevos repertorios (incluso la resistencia armada) y por la integración de la lucha antifranquista catalana con la de aquellos pueblos oprimidos que protagonizaban procesos de liberación nacional y social en el Tercer Mundo.

Si bien la posibilidad de reconocer etapas de flujo y reflujo organizativo y denuncialista en un exilio tan breve como el de los argentinos (1974-1983) parece una operación más compleja, lo cierto es que cuando la noción de "genocidio cultural" se instaló como parte del repertorio de la resistencia exterior (1978/1979), los exiliados estaban en un momento muy productivo y de 
autoconsciencia política. Por un lado, coincide con la etapa de mayor impulso organizativo que multiplicó las casas nacionales, las plataformas unitarias y organizaciones humanitarias y políticas del más diverso tipo. Por el otro, coincide con el momento en que surgieron las principales publicaciones políticas en la diáspora, que cumplieron un papel fundamental en la afirmación de esa dificultosa y tardía autoconsciencia exiliar entre los perseguidos del terrorismo de Estado y en no menor medida en la reflexión y examen del pasado reciente de la Argentina, sus opciones por la violencia, la relación con la democracia, la derrota de los proyectos revolucionarios, etc.

Asimismo, entre la realización del Mundial de Fútbol en Argentina (junio 1978), la visita al país de la Comisión Interamericana de Derechos Humanos de la Organización de Estados Americanos (6-20/9/1979) y la publicación de su informe condenatorio del gobierno militar (abril 1980), los exiliados desplegaron su máximo potencial denuncialista, logrando una colaboración efectiva con las organizaciones humanitarias del interior $-\mathrm{y}$ en particular las Madres de Plaza de Mayo- para la visibilización internacional de las graves, masivas y sistemáticas violaciones a los Derechos Humanos. En esos años, la acumulación y variedad de gestos de condena al régimen militar argentino (desde Carter, Juan Pablo II, la Democracia Cristiana italiana, el gobierno francés, la UCD española ${ }^{61}$ ) parecía poner en evidencia el éxito del trabajo exiliar.

Por último señalar que para ambos exilios, la agitación del "genocidio cultural" coincidió con un momento inicial de reencuentros entre los de "adentro" y los de "afuera". Recordemos que en el caso de España, la rehabilitación internacional del régimen franquista abrió la puerta a un lento y creciente proceso de retornos por goteo, iniciado por aquellos que o bien creían no tener una real significación política como para ser punidos, o bien pretendían sumarse a la oposición interior; y continuado por los que se acogieron a finales de los años 1960 a las amnistías parciales y limitadas del régimen o aprovecharon la relajación de ciertas trabas jurídicas y burocráticas que impedían los retornos (permisos consulares).

En el caso de la Argentina, los primeros contactos fueron el resultado de los viajes turísticos y de consumo de una parte importante de los sectores medios y medio-altos del país que hasta 1979 y en el contexto de la llamada "plata dulce", ${ }^{62}$ se reencontraban con los "subversivos" en Francia, España o EEUU. Cortázar se refirió a esos argentinos calificando su comportamiento como una mezcla de negación de la magnitud represiva y comodidad y resignación ante lo "malo conocido". ${ }^{63}$

\footnotetext{
${ }_{61}$ "El síndrome de Nüremberg”, en Testimonio Latinoamericano, núm. 1, Barcelona, marzo, abril 1980, p. 3.

${ }^{62}$ Hasta finales de los años 1970, en el contexto de la política aperturista del ministro de Videla, José A. Martínez de Hoz, Argentina vivió una primavera económica que fue aprovechada por los sectores medios en una fiesta de consumismo y viajes internacionales a bajos precios. Ya por entonces se observaban los signos del fracaso de la política neoliberal que llevó al país a un enorme endeudamiento externo, el desmantelamiento de la industria nacional y a una escalada inflacionaria que llegó al $100 \%$ anual a finales de 1981.

${ }^{63}$ Carlos Brocato cuestionó esa lectura de Cortázar porque reforzaba una imagen simplista de la Argentina, dividida entre perseguidores y perseguidos $\mathrm{y}$ entre resistentes exiliados $\mathrm{y}$ consentidores- cómplices en el interior. Asimismo denunciaba que al decretar el "genocidio cultural", "apelando a analogías abstractas con el nazismo", no solo estigmatizaba a los represores, sino también a los reprimidos. Para mostrar que todo era "complicidad" y "silencio", Cortázar tuvo que ignorar las múltiples resistencias y la "cultura de catacumbas". BROCATO, Carlos El exilio es nuestro, Sudamericana-Planeta, Buenos Aires, 1986, pp. 156-166.
} 
Pero más allá de estos encuentros en los países del destierro, de una tímida difusión de la producción literaria exiliar en el mercado editorial argentino y de la creciente presencia de las voces de artistas e intelectuales exiliados en la prensa nacional (Humor, Punto de Vista, Nueva Presencia), ya para 1979, se producían algunos tempranos retornos, alimentados tanto por la expectativa regional (amnistías en Chile y Brasil), como por el llamado de Videla a la normalización institucional. Como explicaban los argentinos nucleados en el Club para la Recuperación Democrática de Madrid, desde fines de 1979, se observaban retornos de "personas de cierta notoriedad política, cultural o profesional", "una discreta campaña lanzada desde círculos de la Embajada en Madrid y dirigida a personas concretas" y "la no tan discreta y menos personalizada" campaña de ciertas "organizaciones privadas" (Comité de Estímulo a los Universitarios Argentinos en el Exterior), para "recuperar la mayor cantidad de exiliados" -o mejor dicho de científicos, profesionales universitarios y mano de obra calificada. ${ }^{64}$

2. Aunque después de 1953 y tras la derrota de la guerrilla rural y urbana, la represión no desapareció al punto de que los últimos fusilamientos del régimen franquista corresponden a septiembre de 1975, aquella asumió nuevas formas e intensidades tanto en el plano de la violencia física, como en la de lo económicosocial y cultural. Como afirma Jorge Marco, "a la altura de 1953, los integrantes de aquella generación (la de la República) o estaban muertos, o en la cárcel o en el exilio o simplemente agotados", recluidos en el "pequeño espacio de la esfera privada, preocupados principalmente por su supervivencia". ${ }^{65}$

En paralelo y sobre todo a partir del Plan de Estabilización de 1959, el gobierno de Franco pretendió inaugurar la nueva España del consumo, el turismo, la modernización económica, las políticas desarrollistas y tecnocráticas. ${ }^{66}$ La retórica legitimadora de la "Paz" fue el paraguas simbólico de lo que los exiliados denunciaban como intentos de lavado de rostro del régimen, dirigidos no solo a la vieja oposición republicana sino sobre todo a las nuevas generaciones de hijos de la guerra civil en el interior y el exterior.

En un contexto donde el régimen ya no parecía tener mayores desafíos internacionales y había logrado "limpiar políticamente" el país, la intensidad represiva (y liberalizadora) se amoldaron a las coyunturas de mayor o menor activación social y política interior (huelgas, manifestaciones, acciones armadas, articulación de frentes políticos, etc.).

Parece claro que entre los exiliados del CNC apostar por la institucionalización de la denuncia en foros internacionales y condensarla en torno a la bandera del "genocidio cultural", fue el modo más eficaz para que ni los gobiernos ni las sociedades extranjeras, ni los connacionales en el interior y en el exilio, cayeran bajo los cantos de sirena del reconocimiento del plurilingüismo (Consejo de Falange de Madrid, 1962), las autorizaciones selectivas de la censura, la nueva ley de prensa de Fraga Iribarne (1966), el apoyo del régimen al catalán literario y la creación de cátedras universitarias en

\footnotetext{
64 “EL Club para la Recuperación Democrática Argentina y el operativo retorno”, en Resumen de Actualidad Argentina, núm. 25, Madrid, 1/8/1980, p. 1.

${ }^{65}$ MARCO, Jorge "Limpieza política en España. Insurrección, Guerra Civil y Posguerra (19361953)", en ÁGUILA, Gabriela y ALONSO, Luciano Procesos represivos y actitudes sociales. Entre la España franquista y las dictaduras del Cono Sur, Prometeo, Buenos Aires, 2013, p. 95.

66 CASANOVA, Julián (coord.) Morir, matar, sobrevivir. La violencia en la dictadura de Franco, Crítica, Barcelona, 2012, pp. 15-17.
} 
Madrid o Barcelona o las pequeñas "autorizaciones folklóricas" (bailar sardanas).

A casi 25 años de la derrota republicana, la denuncia del "genocidio cultural" operaba tanto de alerta (interior e internacional) de que la esencia represiva franquista estaba intacta y que cada liberalización debía ser entendida como un gesto oportunista ante la comunidad internacional, que no tardaría en ser rectificado o contradicho; como de táctica para celebrar que pese al intento homicida, el país vivía una "nueva Reinaxença" cultural, integrada a la creciente resistencia política y social del interior (obrera, estudiantil, política, de sectores de la iglesia) y en particular la protagonizada por los jóvenes.

En el caso argentino, la articulación de la denuncia de "genocidio cultural" coincidió con el final de la etapa represiva más severa y la desarticulación definitiva de las organizaciones político-armadas comprometidas entonces en fallidas contraofensivas armadas organizadas desde el exilio.

Pero a su vez, la agitación de "genocidio cultural" se produjo en una coyuntura en la que el gobierno militar buscaba canalizar las tensiones internas (económicas, sociales, e intramilitares), mejorar su imagen exterior, reinventar una nueva legitimación política cuando el argumento de la "guerra antisubversiva" parecía agotado, y mientras se preparaba el recambio del jefe del Estado (el general Roberto Viola sustituía a Jorge Videla en marzo 1981).

En esas circunstancias y mientras la Junta daba a conocer las "Bases Políticas para el Proceso Militar" (diciembre 1979) y llamaba a un "diálogo político" selectivo y desde arriba (marzo 1980), los exiliados percibieron que era importante seguir denunciando el "genocidio" que aún afectaba al campo de la cultura (desde la persistencia de listas negras, que como vimos siguieron operando hasta las elecciones de 1983, los efectos de cesantías y exilios en el mundo académico, etc.), y atenazaba a las familias argentinas con la pregunta por el destino de los "desaparecidos", cuanto más cuando veían alejarse cualquier posibilidad futura de justicia con el artero intento de cierre legal del problema por parte del régimen. Pero además la incardinación de denuncia antidictatorial y "genocidio cultural" fue para los intelectuales en el exilio una forma apelar a lo que concebían como recursos efectivos (y complementarios) al uso de tratados internacionales humanitarios -productos de la segunda posguerra- y a la participación en la creación de otros instrumentos para la defensa de los derechos de los pueblos y la lucha contra el colonialismo y el imperialismo norteamericano (Declaración de Argel, Tribunal Permanente de los Pueblos) o para la realización de una justicia futura (proyectos para la Convención sobre desapariciones).

La apelación a una construcción semántica de tanto peso emocional, de tanto arraigo histórico y con tanta capacidad de multiplicar la solidaridad internacional de diferentes generaciones, sectores políticos y culturas, también debe ser entendida en el contexto de una sociedad argentina en la que crecían las manifestaciones de la voluntad popular por salir de la larga noche dictatorial, audibles en medio de aquellas promesas de apertura política que hacían más evidentes los efectos de los "lavados de cerebros" de quienes habían vivido bajo el terror. En tal sentido, plantear un "genocidio cultural" fue para los exiliados argentinos no solo denunciar los intentos de interdicción o muerte de una cultura y sus cultores, sino también de discutir aquellos mecanismos más sofisticados con los que el régimen había logrado cooptar, domesticar, 
convencer ideológicamente o sumir en la indiferencia a la sociedad en general y a ciertos sectores de la cultura en particular.

Curiosamente mientras los exiliados catalanes con su denuncia del "genocidio cultural" parecieron plegarse a las múltiples resistencias y oposiciones interiores que desde mediados de los años 1960 comenzaron a modificar el clima político y social del tardofranquismo; el uso realizado por los exiliados argentinos operó construyendo una escena polémica al interior del campo intelectual que dificultó comprender el alcance y la potencia de la noción cortaziana en términos de denuncia antidictatorial, lucha antiimperialista y prédica humanitaria.

Bahía Blanca, noviembre de 2017 